\title{
Triflange Acetabular Cup for Severe Acetabular Bone Defect
}

\author{
Yuvraj Agrawal and Bassam A Masri* \\ Department of Orthopaedics, University of British Columbia, Canada
}

Received: November 16, 2017; Published: November 28, 2017

*Corresponding author: Bassam A Masri, Department of Orthopaedics, University of British Columbia, Canada; Email: Bassam.Masri@vch.ca

Abbreviations: CT: Computed Tomogram; 3D: 3 Dimension; BMI: Body Mass Index

\section{Introduction}

Acetabular bone defects in revision hip arthroplasty are a challenging problem. Its treatment relies on preoperative and intraoperative assessment of the size of the defect, presumed quality of the bone, integrity of the acetabular columns and presence of pelvic discontinuity. Several surgical techniques advocated for treating pelvic discontinuity are ilio-ischial cages, plate fixation of structural allograft, triflange cups, Steinmann pin fixation, acetabular revision with additional pelvic screws, acetabular reinforcement rings, oblong cups and cup-cage reconstruction [15]. Severe cases of acetabular bone loss often require an implant specifically made to match the patient's individual anatomy. Triflange acetabular component is a patient-matched implant designed in partnership with the surgeon, using the patient's own computed tomogram (CT) scan data. We present a case with severe acetabular bone loss treated with a custom triflange acetabular cup.

\section{Case Report}

A 59-years old lady presented with gradual worsening pain in her right groin and thigh for a year. More recently, she has noticed progressive shortening of her right leg. The pain with the limb length discrepancy was affecting her function including activities of daily living. She had undergone a primary uncomplicated right total hip arthroplasty in 1986 at age 39 years which was subsequently revised in 1993 for aseptic loosening. She had a past history of Hepatitis C viral infection which she supposedly contracted from a blood transfusion. Other medical illnesses of note were hypothyroidism, osteoporosis and chronic back pain. On examination, she had an obvious limb length discrepancy of $10 \mathrm{~mm}$, a positive Trendelenberg's test, and painful hip range of movements. She was a lean built lady with a BMI of 18. Her preoperative Oxford hip score was $11 / 48$. The plain radiographs (Figure 1) showed loosening of the acetabular component with extensive osteolysis of the periacetabular bone and ballooning of the medial wall. A CT scan was also obtained to establish the extent of bone loss (Figure 2). The 3D reformat images highlighted the significant bone loss further and were utilized to design the patient specific triflange acetabular cup. The custom made triflange acetabular cup was used as it allows for screws to be inserted in to the ilium, ischium and pubic bones to allow fixation of the cup in to the pelvis (Figure 3). A liner was then cemented in the triflange acetabular cup which articulates with the head of the femoral component. Patient has been recently reviewed in the clinic, twelve-months postoperatively, the hip was pain-free and stable (Figure 4).

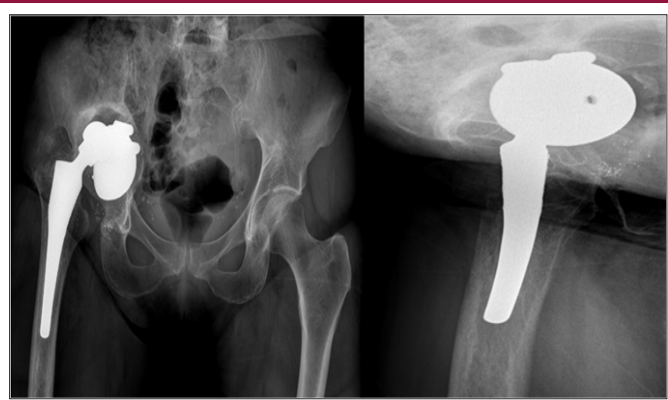

Figure 1: Preoperative radiographs- The right hip acetabular component has loosened and penetrated through the wall of the acetabulum. a. AP view of the pelvis $b$. Lateral view of the hip joint.

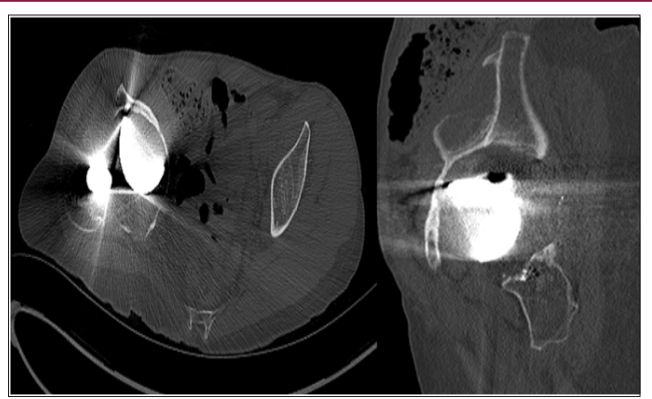

Figure 2: Preoperative CT scan- This is a computed tomography scan of the same patient, demonstrating extensive bone loss, medial acetabular wall fracture with migration of the implant. a. Axial reformat, b. Coronal reformat. 


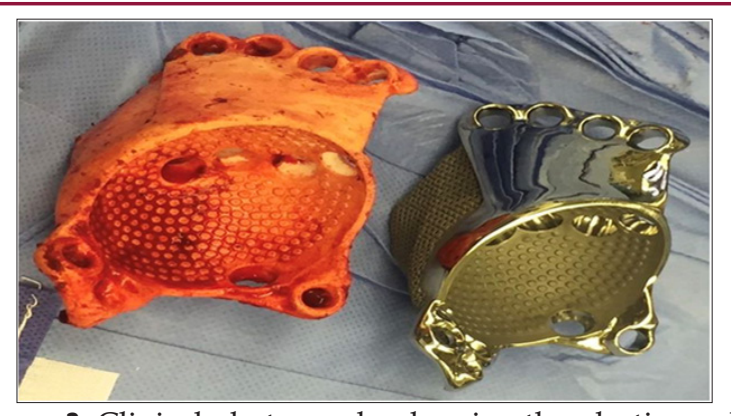

Figure 3: Clinical photographs showing the plastic model for trial and the final custom triflange acetabular cup.

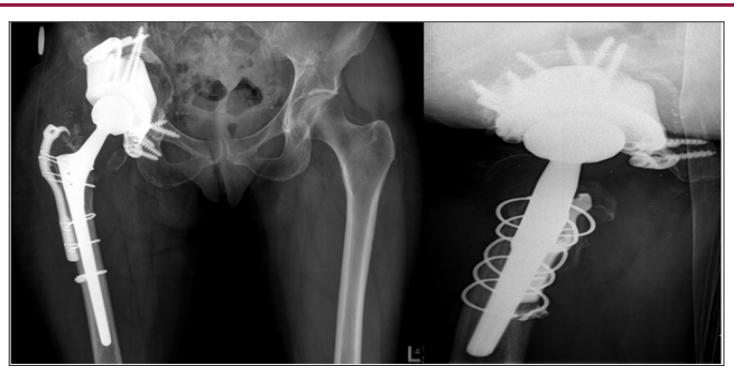

Figure 4: Postoperative radiograph-Six-month postoperative radiographs showing the triflange custom acetabular implant in situ. a. AP view b. Lateral view.

\section{Discussion}

Patients with large acetabular defects and pelvic discontinuity pose a difficult problem for surgeons. The goal of treatment in these cases is fixation with a stable acetabular construct, permitting healing of the discontinuity, and ultimately biological fixation of the acetabular component through osseointegration. If the healing potential of the bone stock is considered to be sufficient, but the defect too large to allow sufficient anchoring with a standard hemispherical uncemented cup, alternative methods of fixation may be required. Extensive bone grafting, porous metal augments, cage or cup cage or triflange acetabular cup may be necessary to restore the pelvic bone stock and augment the reduced acetabular rim. Large defects associated with reduced bone quality should be treated with distraction. Distraction is achieved by a highly porous metal component with metal augments or with the use of custom triflange acetabular components [6]. A cup-cage construct might help to augment construct stability. A polyethylene cup is then cemented into the reconstruction cage [7-8]. The custom designed triflange acetabular components are titanium plasma sprayed, porous or hydroxyapatite coated acetabular components with flanges to aid fixation on to ilium, ischium and pubic bones.

The construct provides the advantage of initial rigid stability until further stability is achieved through the biological fixation of the implant. The use of this implant however requires recognition of the bone loss or pelvic discontinuity in advance to facilitate design and production of the implant and surgeon's co-operation with the manufacturers to check the images, planning and plastic model before the final product is produced using reverse engineering techniques. A prototype of the implant is created using reconstruction of the patient's CT scan data into a 3D bone model (Figure 3). The pelvic model informs the surgeon of the areas of bone to be removed to implant the prosthesis and the trajectory of the screws. In addition, the custom design allows a relatively uncomplicated surgical technique without the need to shape, fit or fix allograft or to bend and fix cages, or augments [9]. Published studies report a high complication rates, particularly instability with an incidence of up to $30 \%$ with the use of these implants [10]. The costs of these custom implants however, were found to be comparable to the trabecular metal cup-cage construct [11]. In summary, the triflangeacetabular cup provides a viable solution for difficult acetabular reconstructions involving severe bone loss or pelvic discontinuity by achieving stable and rigid initial implant fixation on host bone, while it achieves osseointegration.

\section{References}

1. Paprosky, Wayne, Sporer, Scott, Rourke MR (2006) The treatment of pelvic discontinuity with acetabular cages. Clin Orthop Relat Res 453: 183-187.

2. Stiehl JB, Saluja R, Diener T (2000) Reconstruction of major column defects and pelvic discontinuity in revision total hip arthroplasty. J Arthroplasty 15: 849-857.

3. Eggli S, Muller C, Ganz R, Stefan, Christian, et al. (2000) Revisionsurgery in pelvicdiscontinuity: an analysis of seven patients. ClinOrthopRelat Res 398: 136-145.

4. Koster G, Willert HG, Kohler HP, Dopkens K (1998) An oblongrevision cup for large acetabular defects: design rationale and two- to seven year follow-up. J Arthroplasty 13: 559-569.

5. Callaghan JJ, Kim YS, Pedersen DR, Brown TD (1999) Periprosthetic fractures of the acetabulum. OrthopClin North Am 30: 221-234.

6. Sheth NP, Melnic CM, Paprosky WG (2014) Acetabular distraction: an alternative for severe acetabular bone loss and chronic pelvic discontinuity. Bone Joint J 96-B(11 Supple A): 36-42.

7. Springer BD, Berry DJ, Cabanela ME, Hanssen AD, Lewallen DG (2005) Early postoperative transverse pelvic fracture: a new complication related to revision arthroplasty with an uncemented cup. J Bone Joint Surg Am 87: 2626-2631.

8. Boscainos PJ, Kellett CF, Maury AC, Backstein D, Gross AE (2007) Management of periacetabular bone loss in revision hip arthroplasty. ClinOrthopRelat Res 465: 159-165.

9. Christie MJ, Barrington SA, Brinson MF, Ruhling ME, DeBoer DK (2001) Bridging massive acetabular defects with the triflange cup: 2- to 9-year results. ClinOrthopRelat Res 393: 216-227.

10. DeBoer DK, Christie MJ, Brinson MF, Morrison JC (2007) Revision total hip arthroplasty for pelvic discontinuity. J Bone Joint Surg [Am] 89(4): 835-840.

11. Taunton MJ, Fehring TK, Edwards P, Bernasek T, Holt GE, et al. (2012) Pelvic discontinuity treated with custom triflange component: a reliable option. ClinOrthopRelat Res 470: 428-434. 


A Assets of Publishing with us
BESEDICAL

